Anales del Seminario de Historia de la Filosofía

ISSNe: 1988-2564

http://dx.doi.org/10.5209/ASHF.56802

\title{
Giacomo Zabarella: un aristotélico crítico en la era de la revolución científica
}

José Manuel García Valverde

Recibido: 29/02/2016. Aceptado: 03/03/2017

Resumen. Giacomo Zabarella es considerado uno de los aristotélicos más prestigiosos y más influyentes del siglo XVI. Su obra lógica, sus escritos sobre física y sus comentarios, publicados póstumamente, tuvieron un enorme impacto especialmente en las primeras décadas del siglo XVII, y sirvieron como verdaderos manuales con los que se formaron muchos universitarios europeos. Este artículo analiza la figura de Zabarella centrándose en su obra sobre física, el De rebus naturalibus libri XXX, editado en 1590, apenas unos días antes de su muerte.

Palabras clave: Aristotelismo renacentista; Humanismo; Física; Método científico; Zabarella.

\section{[en] Giacomo Zabarella: a critical aristotelian in the age of the scientific revolution}

\begin{abstract}
Giacomo Zabarella is considered one of the most prestigious and most influential sixteenth century Aristotelians. His logic work, his writings on physics and his commentaries to Aristotle's books, published posthumously, had a huge impact especially in the early decades of the seventeenth century, when they became true manuals by which many European students were formed. This article analyzes the figure of Zabarella focusing on his work on physics, the De rebus naturalibus libri XXX, published in 1590 , just some days before his death.
\end{abstract}

Keywords: Renaissance Aristotelianism; Humanism; Physics; Scientific Method; Zabarella.

Sumario: 1. Introducción. 2. Zabarella y el "humanismo" aristotélico tardorrenacentista. 3. Las fuentes filosóficas de Zabarella en el De rebus naturalibus: el análisis crítico de la tradición peripatética. 4. Método empírico y distinción lógica: la originalidad del discurso expositivo de Zabarella. 5. Conclusión.

Cómo citar: José Manuel García Valverde (2017): "Giacomo Zabarella: un aristotélico crítico en la era de la revolución científica", en Anales del Seminario de Historia de la Filosofia 34 (3), 587-609.

\section{Introducción}

Una buena parte de los esfuerzos de la investigación histórica moderna por lo que se refiere a la historia del aristotelismo se ha dirigido a poner de manifiesto cuán alejada está la realidad de ese estereotipo de rigidez, intransigencia e incluso intolerancia que se ha situado sobre las cabezas de los aristotélicos renacentistas, tomados en

$1 \quad$ Universidad de Sevilla.

ORCID: 0000-0003-2865-1895 
conjunto y sin distinciones de ninguna clase. Ese estereotipo, además, se ha construido en base a una contraposición con la riqueza de contenidos y la excelencia estilística del platonismo coetáneo. Esta concepción ciertamente simplista de la historia de la filosofía renacentista no es en modo alguno adecuada para entender ese caudal de textos que se generó especialmente en las universidades del norte de Italia a lo largo del siglo XVI. Esos textos, en efecto, por más que tengan una evidente raigambre aristotélica - no en vano la mayoría de ellos se dedica a la exégesis de las diferentes partes del Corpus aristotelicum-, muestran una gran variedad de tendencias moduladas por la propia historia del aristotelismo tanto antiguo como medieval, así como una naturaleza claramente permeable a las tendencias de crítica textual basada en el conocimiento del griego clásico y de las fuentes clásicas en general. Es decir, el aristotelismo renacentista, al menos en la segunda mitad del siglo XVI, compartió criterios interpretativos con el humanismo, y por ello se ha hablado de un aristotelismo humanista, más allá de la enorme variedad de puntos de vista que los propios aristotélicos han manifestado acerca del sentido verdadero, de la coherencia interna o de las propias lagunas que los textos de Aristóteles presentaban al lector crítico.

De hecho, se puede delinear con bastante claridad la clase de aristotelismo de un autor determinado en virtud precisamente de la forma en que ese autor recurre a los propios textos del maestro. Y, como Charles B. Schmitt ha puesto de manifiesto ${ }^{2}$, la variedad de recursos textuales es tan grande que el calificativo genérico de "aristotélico" corre el riesgo de perder nitidez. Ciertamente hay muchos autores del siglo XVI, considerados o no como aristotélicos, que comparten el hecho de referirse a los textos de Aristóteles para comprender o tratar de comprender uno o varios aspectos de la naturaleza. Sin embargo, ese recurso es tan variado que fluctúa desde una adhesión servil hasta la simple adopción de ciertos criterios metodológicos que están presentes de una manera más o menos explícita en los escritos lógicos del Estagirita. En este sentido, hubo quienes aceptaron en bloque el Corpus aristotelicum al completo, hubo quienes sólo aceptaron los escritos morales y políticos, otros -en fin- sólo el organon.

En muchos casos, las fuentes filosóficas se mezclaron generosamente de tal manera que el resultado fue una amalgama que anunciaba una filosofía nueva que ya no era ni puramente aristotélica ni puramente platónica. Aquí las categorías que se han aplicado en los grandes manuales de historia de la filosofía suelen ofrecer una visión grosera del pensamiento renacentista dividido entre seguidores del aristotelismo, seguidores del platonismo o seguidores del hermetismo, por poner algunos ejemplos. Cuando se aplica el foco a lo concreto y se leen las obras de unos y de otros, se llega a la conclusión de que en el Renacimiento, con algunas excepciones muy particulares, lo que verdaderamente prevaleció fue el eclecticismo entre tradiciones filosóficas que hunden sus raíces en la Antigüedad y en la Edad Media. El ya mencionado Ch. B. Scmitt lo decía con gran énfasis ${ }^{3}$ : hay que considerar a los autores como individuos, no como piezas inertes de una escuela monolítica.

Es cierto, por lo demás, que el término "aristotélico" sigue teniendo un cierto valor en cuanto remite a un escenario en el que se movieron muchos autores que, sin embargo, no tuvieron inconveniente alguno en tomar materiales de otras corrientes filosóficas, especialmente de la tradición platónica.

Schmitt 1983, p. 14.

Schmitt 1983, p. 102. 


\section{Zabarella y el "humanismo" aristotélico tardorrenacentista}

Desde luego uno de esos autores es Giacomo Zabarella. Su carrera universitaria nos es bien conocida: sobrino de Marcantonio Genua y perteneciente a una noble familia paduana, recibió una esmerada educación humanística y llegó a alcanzar una gran maestría en el griego clásico, la cual aún en nuestros días es admirada y utilizada por algunos especialistas modernos ${ }^{4}$. En la Universidad de Padua tuvo ilustres maestros, como correspondía a la época de esplendor de estos studia: en humanidades recibió enseñanzas de Francesco Robortello, en lógica de Bernardino Tomitano, en filosofía natural y metafísica del ya citado Genua, y en matemáticas de Pietro Catena. En 1564 obtuvo la primera cátedra de lógica, sucediendo a su maestro Bernardino Tomitano; seis años más tarde pasó a ocupar la segunda cátedra extraordinaria de filosofía natural (un puesto más prestigioso y más lucrativo que el primero); en 1577 promocionó a la primera cátedra extraordinaria de filosofía natural y finalmente en 1585 obtuvo la segunda cátedra ordinaria de filosofía natural -la primera le estaba vetada por los Estatutos de la Universidad de Padua, que impedían esta promoción a los nativos de la ciudad $-^{5}$.

En todo caso, Zabarella gozó en vida de un extraordinario prestigio, especialmente en el ámbito de la lógica y la metodología científica: sus escritos en este ámbito tuvieron un recorrido editorial amplísimo que se adentró largo trecho en el siglo XVII y alcanzó puntos muy distantes de la geografía europea ${ }^{6}$. De hecho, fueron requeridos sus servicios como docente por el rey de Polonia, a lo que Zabarella rehusó para permanecer en su ciudad natal hasta el día de su muerte en octubre de $1589^{7}$.

Si de su vasta producción literaria centramos nuestra atención en el enciclopédico tratado de filosofía natural titulado precisamente De rebus naturalibus, publicado originalmente en $1590^{8}$, constatamos de inmediato que más allá del paradigma aristotélico en el seno del cual está escrito, su autor utiliza una enorme cantidad de fuentes que integran tanto la tradición aristotélica, como la platónica y en general todo lo que pudo alcanzar como testimonio de un afán por comprender, de manera acertada o no, el funcionamiento de la naturaleza. En este sentido, la obra representa un enorme esfuerzo por desentrañar cada una de las cuestiones que se plantean en el ámbito de la filosofía natural, y cada uno de los innumerables debates que se han abierto a lo largo de la historia del aristotelismo, a través de un discurso demostrativo que trata de alcanzar la verdad, primero, y luego de adecuar, en la medida de lo posible, los propios textos de Aristóteles a esa verdad: véase, por ejemplo, lo que el propio Zabarella señala en el libro tercero del De rebus naturalibus, en donde tratando el tema de la materia prima declara con toda contundencia: "Por ello, como quiera que he considerado este asunto con diligencia, y que siempre he pensado que hay que buscar de cualquier cosa, antes que nada, la verdad, y que después, una vez que la conocemos, hay que llevar a ella, si es posible, las palabras de Aristóteles, no al

4 Cfr. Hicks 1965, p. LXV, n. 4; Ross 1961, p. 44; Randall 1960, pp. 99, 101 y 103; Owens 1976, p. 108; Tracy 1982, p. 98; Kal 1988, p. 108; Valverde 2012, pp. 27-56.

Cfr. Mikkeli 2012.

Cfr. Kuhn 2002, pp. 83-122; Maclean 2002, pp. 173-213; Mikkeli 2002, pp. 257-309.

Cfr. Edwards 1960, pp. 1-82; Maclean 2002, p. 182.

Iacobi Zabarellae Patavini De rebus naturalibus libri XXX. Quibus quaestiones, quae ab Aristotelis interpretibus hodie tractari solent, accurate discutiuntur, Venetiis, apud Paulum Meietum, Bibliopolam Patavinum, 1590. A partir de ahora abreviaremos el título de la obra como $D R N$ y utilizaremos la paginación de esta primera edición, a la que se puede acceder fácilmente a través de la Internet. En estos momentos estamos terminando una edición de esta obra para la editorial holandesa BRILL. 
revés, como muchos hacen (...), he pensado que lo que hay que decir necesariamente es que o bien Aristóteles diría esto mismo, o bien diría una falsedad" ".

Así pues, observamos cómo Zabarella es capaz de poner la razón por delante de Aristóteles como guía de un estudio de la realidad que pretende estar libre de toda interferencia religiosa o incluso metafísica. Sin adelantar nuestro juicio sobre si supo él llevar a buen puerto esa pretensión, lo cierto y verdad es que la visión que se ha tenido desde muy pronto de la figura de Giacomo Zabarella abunda en la imagen de un pensamiento riguroso, sistemático e independiente.

Ya Pierre Bayle ${ }^{10}$ se refería a él con apelativos elogiosos y no dejaba de subrayar que su pluma había legado obras que suponían un notable progreso en el terreno de la lógica y en el de la física (además - dice Bayle- de en el de las matemáticas); subrayaba igualmente la faceta hermenéutica de Zabarella en torno a las obras de Aristóteles con comentarios que "firent connaître que son esprit était capable de débrouiller les grandes difficultés, et de comprendre les questions les plus obscures".

Desde luego, esta faceta interpretativa de Zabarella ha sido celebrada por la crítica moderna, y se ha incidido en el hecho de que el profundo conocimiento que había adquirido del griego clásico le permitía tener una visión privilegiada de las dificultades y de las fallas que presentaban los textos de Aristóteles. De este modo, la figura de Zabarella representa la expresión quizá más perfecta de ese nuevo aristotelismo que se había pertrechado de los instrumentos filológicos del humanismo para alcanzar una lectura "moderna" de aquellos textos. Paul O. Kristeller así lo indicaba, señalando que de esta manera Zabarella representaba la etapa última del aristotelismo renacentista y se presentaba ante la posteridad como una de las cabezas más lúcidas en la tarea de desentrañar los grandes nudos interpretativos que los escritos de Aristóteles suponen para los lectores de cualquier época: "había adquirido un dominio completo del Aristóteles griego y de sus comentaristas, y por ello ha sido alabado por los estudiosos modernos no sólo como un buen filósofo, sino también como uno de los comentaristas de Aristóteles mejores y más lúcidos de todos los tiempos."11

Estamos, pues, ante la visión de un Zabarella al que muchos no han dudado en considerar un verdadero humanista, por más que sus competencias en el ámbito del griego no sean del nivel de las de un Poliziano o un Lambin. En todo caso, él tenía sin duda una buena formación filológica, un sólido conocimiento del griego y una amplísima cultura literaria clásica, además de un profundo conocimiento de la historia de la filosofía antigua, medieval y contemporánea. Todo ello le servía, como indica Schmitt, para reflexionar sobre la letra de los textos, sobre su sentido y sobre la mejor manera de transmitirlo a sus lectores ${ }^{12}$.

$9 \quad$ Zabarella $D R N$, III, p. 137: "Quamobrem cum ego rem hanc diligenter consideraverim, semperque existimaverim quaerendam semper esse ante omnia cuiusque rei veritatem, deinde illa cognita, ad eam, si fieri possit, verba Aristotelis trahenda esse, non e contrario, quod multi faciunt, (...) dicendum censui necesse esse ut Aristoteles vel hoc idem dicat, vel falsum dicat." Cfr. Palmieri 2007, p. 410, quien encuentra lo que él denomina "three types of promise of allegiance" en el De rebus naturalibus de Zabarella: por un lado está la afirmación expresamente realizada por Zabarella de que su propósito no es otro que el de explicar el punto de vista de Aristóteles; por otro lado, encontramos también la promesa de acceder a la verdad misma de acuerdo con el pensamiento de Aristóteles; y finalmente encontramos ciertos momentos, no muy numerosos, en los que Zabarella explícitamente se distancia del parecer de Aristóteles o al menos tiene grandes dificultades para hacer concordar su parecer con el de Aristóteles.

10 Bayle 1820, XV: "Zabarella", p. 5.

11 Cfr. Kristeller 1979, p. 46.

12 Cfr. Schmitt 1983, p. 19; Edwards 19692, pp. 843-854. 
Lo mismo podemos encontrar en otros especialistas modernos: así, por ejemplo, William A. Wallace ha señalado la influencia que el humanismo había ejercido sobre muchos aristotélicos tardíos entre los cuales está en posición preeminente Zabare$11 a^{13}$. Esta concepción de la paulatina "humanización" del aristotelismo renacentista representa, en realidad, una de las características de este aristotelismo sobre la que han puesto el acento muchos de los historiadores más renombrados de este período. Así, lo podemos encontrar en E. Garin, Ch. H. Lohr, el ya citado C. B. Schmitt, E. Kessler y otros muchos ${ }^{14}$.

Pero tampoco podemos olvidar que precisamente en esa preponderancia de la faceta interpretativa se ha visto, en términos generales y en referencia a la figura de Zabarella en particular, un grave obstáculo y una de las causas de la decadencia del propio aristotelismo. Así, por ejemplo, Antonino Popp ${ }^{15}$ ha dirigido en más de una ocasión una visión profundamente crítica sobre un modo de filosofar que, más que interesado en alcanzar la verdad en sí, parece volcado en exponer el pensamiento de un autor concreto, lo que suponía una enorme restricción para la investigación de los verdaderos problemas que urgía abordar sobre el mundo y el hombre. Por ello, se ha considerado que el propio afán enciclopédico de Zabarella a la hora de cerrar todas las heridas sangrantes de la tradición peripatética representa en realidad el canto del cisne de un modo de hacer filosofía que iba a ser relegado definitivamente a la vuelta de la esquina por una nueva ciencia y un nuevo método científico.

Esta visión, por lo que se refiere concretamente a Zabarella, ya había sido formulada en el siglo XIX por el propio Ernest Renan ${ }^{16}$, pero no podemos olvidar que ha tenido también a lo largo del siglo XX una fuerte réplica por parte de otros especialistas que han señalado que Zabarella es un digno representante de una nueva forma de pensamiento que, sin romper con la tradición, se presentaba con una nueva forma, un método volcado en la observación empírica y una visión crítica del propio aristotelismo que lo hacían precursor de la filosofía moderna. E. Kessler, por ejemplo, no tiene inconvenientes en poner en paralelo el método de Descartes con el de Zabarella para hacer a éste muñidor de una nueva forma de entender los procedimientos metodológicos: al desvincularlos, como hizo Zabarella, de la psicología y presentarlos

13 Wallace 1988, p. 209: "Since Aristotle was the main authority, commentaries on his writings were an important vehicle, but these were supplemented by "questionaries" that treated disputed points and school positions in exhaustive detail. This scholastic mode influenced medical writing as well as that on nature throughout the fourteenth and fifteenth centuries. Under humanist influences, however, the later Renaissance saw a reaction against scholastic method and the arid treatises it tended to produce. Particularly in Italian universities a more discursive and literary style was adopted, with classical allusions and more attention to philology and the Greek text. The works of Nifo and Zabarella, to say nothing of Boccadiferro, Buonamici, Cremonini, Mazzoni, Pendasio and Porzio, are very different from those of Paul of Venice or Blasius of Parma, and that simply on the basis of style of argument and presentation of results".

14 Cfr. Bianchi 2003, pp. 148-149.

15 Cfr. Poppi 2004, p. 40: "I have particularly focused on Zabasella's first discourse because it conveys Zabarella's rigorous conception of philosophizing. However, it also stresses the limits of a servile interpretation of somebody else's thought, because of the depersonalization of the problem and the experience of the thinking subject, even of the most intimate requirements of one's religious conscience. More than at truth, it seemed that at that time philosophy should have aimed at the faithful exposition of an author's thought. Philosophy was not supposed to extend its domain of research beyond the issues dealt with by the interpreted author; it was supposed to ignore or put into brackets the problems of one's own existence and of human history. From this, we understand the necessity and fecundity of the turn inaugurated by modern thought when scholars started to interrogate directly the whole of human experience, nature, the heavens, and God himself beyond the filters of a commentary to what Aristotle said about them or his several, often contradictory, expositors."

16 Cfr. Renan 1852, p. 319. 
como producto únicamente de la deliberación y de la voluntad humana, y por ello subrayar su carácter arbitrario, no estaba haciendo otra cosa que avanzar los caminos por los que la epistemología transitaría en el siglo XVII ${ }^{17}$.

Por lo demás, la pretensión expresada por Zabarella al comienzo del De rebus naturalibus ${ }^{18}$ de reducir a una unidad metodológicamente bien sustentada todos los libros naturales de Aristóteles, para de esta manera determinar bien el objeto propio de la ciencia natural y desvincularla de otras formas de conocimiento (esto es, la metafísica y la teología), se ha entendido como una verdadera declaración de principios: Zabarella, como señalaba Giuseppe Saitta $^{19}$, se adhería con visible complacencia a la ciencia natural como el estudio que mejor se adecúa al filósofo, puesto que sólo en tal terreno éste puede moverse con independencia y guiarse únicamente por unos principios bien establecidos; la ciencia natural tiene como objeto genérico nada más que el cuerpo tomado en general (universe sumptum), y de este modo ella es capaz de comprender todas las cosas celestes y terrenales, pues el cuerpo natural posee en sí la naturaleza, que es el principio del movimiento ${ }^{20}$.

Y ello a través de un método que destacaba la importancia de la observación y consideraba que sólo a través de esta puede llegarse a un primer conocimiento de la causa que, posteriormente, a través de un cuidadoso análisis se perfilará definitivamente: más allá del debate sobre si esta concepción tuvo o no influencia en los procedimientos metodológicos que desarrolló Galileo ${ }^{21}$, lo cierto es que Zabarella es considerado como la culminación de un proceso que se había desarrollado en la Universidad de Padua; a lo largo de este proceso se había debatido qué naturaleza tenían los escritos lógicos de Aristóteles y cómo debían ser instrumentalizados en el camino de la adquisición y el atesoramiento del conocimiento científico. Cuando insistía en que el filósofo de la naturaleza debe aplicarse a un concienzudo análisis de la observación para desvelar todos los elementos que ésta ofrecía al observador con el fin de descubrir en ella los principios y las causas de la naturaleza, Zabarella anunciaba un nuevo tiempo en la ciencia ${ }^{22}$. Es cierto que él mismo seguía aún imbui-

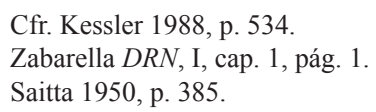

Cfr. Kessler 1988, p. 534.

Zabarella $D R N$, I, cap. 1, pág. 1.

Saitta 1950, p. 385.

20 Zabarella $D R N$, I, cap. 2, pág. 2-3: "Sed hoc cognoscere non satis est: cum enim scientia naturalis una sit, et unitas scientiae sumatur ex unitate subiecti, oportet res omnes naturales praedictas sub unum aliquod genus reducere, quod eas omnes complectens dicatur subiectum unum totius naturalis philosophiae et ipsi toti adaequatum. Hoc igitur quodnam statuendum sit interpretes Aristotelis superioribus temporibus non consenserunt, fuitque inter eos maxime controversum. Sed hac tempestate videntur omnes in hanc sententiam convenisse, quod corpus universe sumptum, quod et caelestia et inferiora omnia complectatur, quatenus naturale, hoc est, quatenus habens in seipso naturam, quae motus principium esse definitur, sit commune subiectum totius scientiae naturalis; quam sententiam ego absque dubio veram esse censeo, cum et Aristotelis testimonio satis claro et efficaci ratione comprobetur."

21 Cfr. Randall 1961, p. 23; Schmitt 1969, pp. 80-138; Poppi 2004, p. 49.

22 Randall 1961, pp. 55-56: "The originality of Zabarella, and of the whole development of which he is the culmination, is thus to set off a 'scientific experience' from mere ordinary observation, the accidental or planless collection of particular cases. The weakness of the logic of the Schoolmen had lain precisely in their acceptance of first principles established by mere common observation. In contrast, Zabarella, and with him the whole new science, insisted that experience must first be analysed carefully to discover the precise 'principle' or cause of the observed effects, the universal structure involved in them. After this analytic way of discovery has been pursued, we are then in a position to demonstrate deductively how facts follow from this principle or cause: we can pursue the way of truth. Scientific method, that is, proceeds from the rigorous analysis of a few selected instances or illustrations to a general principle, and then goes from that principle back to the systematic and ordered body of facts, to the science itself formally expressed. Zabarella calls this the combination of the resolutive and 
do de la tarea interpretativa de la obra de Aristóteles, y ello le imposibilitaba el uso creativo que un Galileo le dio después a la experiencia para convertirla en verdadera experimentación ${ }^{23}$, pero eso no quita mérito al hecho de que Zabarella en el terreno del debate metodológico tuvo un papel fundamental.

Supo, por otro lado, modernizar el discurso expositivo y dotarlo de una claridad y una viveza raramente alcanzada entre sus coetáneos. Con él, la típica estructura de la quaestio, que seguía siendo la forma en que los aristotélicos organizaban sus escritos cuando no se dedicaban al comentario específico de una obra de Aristóteles, alcanzó una nueva dimensión y se abrió hacia una nueva forma de expresión filosófica en la que se priorizaba de una forma contundente la claridad de la exposición por encima de una estructura expositiva rígidamente encorsetada. Ciertamente, la prosa de Zabarella está desprovista de adornos innecesarios, pero eso no hace aburrida su lectura; al contrario, es muy ágil y muy clara, y por eso sus textos son enormemente útiles para seguir sin dificultad el hilo de los argumentos, las referencias a los otros autores y la exposición de los textos en torno a los cuales ha habido debate a lo largo de la historia del aristotelismo. Si, en efecto, se quiere tener una visión de conjunto del aristotelismo renacentista o una perspectiva más enfocada en las numerosas discusiones que, en el ámbito concretamente de la filosofía natural, se desarrollaron en su seno, sin lugar a dudas el De rebus naturalibus es una lectura muy recomendable; no en vano, fue un texto enormemente leído a comienzos del siglo XVII sobre todo en Alemania, como testimonia el gran número de ediciones que tuvo en las primeras décadas del siglo ${ }^{24}$.

Porque Zabarella era muy eficaz a la hora de delimitar con exactitud y claridad el problema concreto que iba a abordar. Quitando el primer libro, que tiene un carácter más bien introductorio, y está destinado a desarrollar una presentación ordenada de los escritos naturales de Aristóteles, en el resto de los libros, que pueden ser independientes o estar ordenados en torno a una temática común, el lector no tiene dificultad en conocer de manera precisa qué cuestión se va a tratar, qué problema encierra esta cuestión, cómo se va a abordar su dilucidación y cuál es la solución que se le da.

$\mathrm{Y}$ todo ello a través de una secuencia de contenidos que acoge ciertas variaciones. No es monolítico Zabarella en su exposición. Siendo, como es lógico, común el hecho de que se exponga al inicio el problema que se va a debatir, el autor unas veces abre su particular análisis exponiendo las soluciones que otros han dado a la dificultad planteada y cuestionando la validez de esas soluciones para después exponer la suya propia; otras veces, sin embargo, Zabarella expone su propia opinión sobre la cuestión inmediatamente después de plantearla, para posteriormente analizar las objeciones que se pueden dar o se han dado efectivamente a su opinión y resolver esas objeciones. En todo caso, vaya antes o después, la exposición de la resolución de la cuestión planteada va siempre seguida de un estudio detallado de las consecuencias que esa resolución tiene y cómo se acomoda con el pensamiento que otros autores, mayormente aristotélicos, han manifestado al respecto a lo largo de la historia. En ciertas ocasiones, además, Zabarella recoge en un capítulo un resumen somero de los

the compositive methods and such were precisely the procedure and the terms of Galileo. The presupposition of this method is of course that there exists an intelligible structure in the subject-matter under examination, of which the particular cases observed by the senses are instances; Zabarella makes this perfectly plain."

23 Cfr. Schmitt 1969, p. 124.

24 See Maclean 2002, p. 190-198; Kuhn 2002, pp. 83-122. Para un análisis del florecimiento de manuales de filosofía en este período, véase Schmitt 2002, pp. 792-805. 
principios y fundamentos que deben tenerse en cuenta para solucionar un problema, y en otras esos principios van desgranándose a lo largo del discurso, generalmente como consecuencia de la confrontación con otras opiniones más o menos afines a la suya.

En todo caso, más allá de esta variedad de formas de afrontar los distintos temas que Zabarella aborda a lo largo de las numerosas páginas del De rebus naturali$b u s$, la verdad es que el desarrollo de sus argumentos tiene ciertamente un reducido número de pautas fácilmente identificables. En primer lugar, como acabamos de señalar, hay un permanente diálogo crítico con la tradición peripatética o no peripatética, de modo que Zabarella siempre encuentra necesario detallar qué es lo que otros han dicho sobre el tema en cuestión y qué contradicciones pueden hallarse en ellos bien sea con los textos de Aristóteles, bien sea con los principios de la filosofía peripatética, bien sea con lo que la razón dicta o la experiencia reclama. En el ámbito del aristotelismo, el De rebus naturalibus alberga un sinfín de referencias que alcanza la práctica totalidad de la tradición aristotélica antigua, medieval y, en buena medida, renacentista. Además, si fijamos nuestra atención en las grandes luminarias Zabarella es exhaustivo en cuanto a la exposición de las distintas teorías naturales que habían formulado desde un Alejandro de Afrodisias, desde un Avicena o un Averroes, desde un Tomás de Aquino o un Alberto Magno, hasta los más recientes Nifo, Pomponazzi o Zimara, por referirnos a algunos de ellos. Con respecto a todos ellos, Zabarella exhibe un criterio de análisis y discusión que pretende ser independiente y leal sólo a la verdad y a una legítima lectura de Aristóteles.

\section{Las fuentes filosóficas de Zabarella en el De rebus naturalibus: el análisis crítico de la tradición peripatética}

Sin embargo, es un tema controvertido el de las influencias que Zabarella recibe en cuanto a los autores peripatéticos que él generosamente cita. Varios trabajos han tratado de una manera más o menos central el alejandrismo de Zabarella, su forma de recibir el averroísmo tanto medieval como renacentista, o su visión de los escolásticos ${ }^{25}$.

Si centramos nuestro foco de atención de nuevo en el De rebus naturalibus basta un somero vistazo al índice de autores referenciados para darnos cuenta de que, a mucha distancia de los demás, Averroes se lleva la palma en cuanto a su presencia en los treinta libros que componen la obra. Este hecho no tiene por qué ser en sí significativo para determinar un ascendiente averroísta en el pensamiento de Zabarella; sin embargo, si analizamos el peso del uso que hace Zabarella de Averroes y en qué momentos se decanta por acoger el parecer del filósofo cordobés como coherente con la verdad y con la razón, percibimos que su presencia es sin duda destacadísima. A la luz de los textos, Averroes es la figura más importante en la obra, es la voz autorizada que Zabarella suele seguir en los temas más dificultosos, de modo que no cuesta trabajo concluir que para él Averroes es, a pesar de que no tuvo acceso en griego a las obras de Aristóteles, el que mejor lo entendió y el que mejor lo interpretó. Es

25 Para la presencia de Alejandro en Zabarella, véase Kessler 1988, pp. 530-534; Kessler 2011, pp. 49-58. Para la influencia de Averroes, Edwards 1960, pp. 91-107; Martin 2007, pp. 3-19. Pueden encontrarse muchas otras referencias en Mitrovic 2009, pp. 330-354; Palmieri 2007, pp. 404-427. 
suficiente un somero repaso a las cuestiones que trata Zabarella y a la solución que les dio para darnos cuenta de la fuerza con la que esgrime el poder interpretativo del filósofo cordobés. Los ejemplos que podríamos poner son innumerables y aparecen desde el principio. En el libro primero Zabarella adopta una y otra vez la opinión de Averroes acerca del orden en el que deben ser leídas las obras naturales de Aristóteles y de cómo debe entenderse la organización interna de los contenidos ${ }^{26}$. En los libros II y III, centrados en el tema de la materia prima, Zabarella acepta un serie de consideraciones de Averroes que resultan cruciales para la determinación de su propia postura: ambos coinciden en la manera en que puede ser accesible al físico, que trata acerca de cuestiones que están al alcance de los sentidos, una cosa tan recóndita como es la naturaleza de la materia prima ${ }^{27}$; ambos coinciden igualmente en cómo debe considerarse la potencia como esencia de la materia ${ }^{28}$; contra Tomás Zabarella acude a la consideración que hace Averroes de la materia como cantidad intermina$t a^{29}$; y finalmente Zabarella adopta la opinión de Averroes en la crucial concepción de la materia como cuerpo en contra de una buena parte de la escolástica y del aristotelismo medieval ${ }^{30}$. Más tarde, ya en el libro cuarto, que estudia desde un punto de vista general la definición del concepto de naturaleza, Zabarella sigue adoptando la opinión de Averroes como fundamento de la suya propia, por ejemplo la idea de que la forma, como depositaria de la naturaleza del sujeto, es el principio tanto activo como pasivo del movimiento ${ }^{31}$. En el célebre libro quinto, donde Zabarella aborda la forma en que el físico puede conocer la existencia del motor inmóvil, él no hace sino glosar y extraer todas las consecuencias de la argumentación formulada por Averroes contra Avicena según la cual el único medio para demostrar la existencia del motor inmóvil es el movimiento ${ }^{32}$.

Así pues y sin ánimo de agotar todos los puntos en que el filósofo paduano coincidió con Averroes, podemos decir que en casi todos los ámbitos esta coincidencia es

26 Cfr. Zabarella $D R N$, I, cap. 5, pág. 11; cap. 6, pág. 12-13; cap. 9, pág. 15; cap. 21, pág. 39; 41; cap. 27, pág. 53; cap. 30 , pág. 60 , etc.

27 Zabarella $D R N$, II, cap. 5, pág. 94.

28 Zabarella $D R N$, II, cap. 11, pág. 109-110.

29 Zabarella $D R N$, III, cap. 9, pág. 133.

30 Zabarella $D R N$, III, cap. 18, pág. 149-150. Por un lado, está la opinión de Santo Tomás y de una buena parte de sus acólitos, quienes señalaban que no puede ser corpórea por carecer de cantidad, que únicamente se adquiere con la llegada de la forma. Por el contrario, para Averroes la materia por sí misma y antes de recibir la forma tiene cantidad y posee las tres dimensiones. Zabarella se decanta por esta segunda opinión: la cantidad, entendida como no suscrita a ningún límite, es inherente a la materia y constituye una propiedad de ella. La ratio corporis no podemos buscarla ni en un accidente de la substancia corpórea, ni en una propiedad sobrevenida de la unión de dos componentes -forma y materia- que fueran por sí incorpóreos; de modo que, concedido que la forma es per se incorpórea, sólo resta que lo que aporte la corporeidad al compuesto sea la materia. Por tanto, en palabras de Zabarella, «la materia no sólo es corpórea, sino que es el cuerpo mismo (corpus ipsum), el cual es puesto en la categoría de la substancia en el género más alto». Carece, por tanto, la materia prima de contrario, y por ello pertenece al género más universal de la substancia. Otorga a todo lo que es corpóreo la cualidad que ella es en el máximo grado; ahora bien, ¿qué es lo que otorga a todo lo demás? «el cuerpo substancial es aquella substancia que está sujeta a las tres dimensiones». Por ello, continúa Zabarella, «parece que el nombre de cuerpo significa principalmente las tres dimensiones», por lo que el cuerpo es el substrato de las tres dimensiones, ya que éstas tienen que estar adheridas a algún sujeto. En conclusión, la materia prima es un género de substancia al que el cuerpo sirve de substrato y las tres dimensiones de una primitiva determinación; toda otra determinación cuantitativa y cualitativa llegará con la forma: «Quia si materiam mente contemplemur abiunctam a formis, nil aliud concipere possumus nisi corpus quoddam vastum et indistinctum, et molem quamdam vacuam, ut dicebat Plotinus». (Cfr. G. Zabarella, DRN, lib. III: De prima rerum materia, cap. 17, p. 298).

31 Zabarella $D R N$, IV, cap. 7, pág. 167.

32 Zabarella $D R N$, V, cap. 1, pág. 174. 
fácilmente identificable por cuanto que Zabarella no tiene inconveniente alguno en hacer explícitamente suyo el pensamiento del cordobés. Si avanzamos, por ejemplo, hacia el libro X, en el que Zabarella hace una incursión en el terreno de la metafísica para estudiar la causa de la constitución del individuo, su opinión coincide al cien por cien con la de Averroes: una tal causa sólo puede ser la forma, y de ninguna manera la materia ${ }^{33}$. Cuando más tarde se trata la difícil cuestión de la mezcla y la determinación de su naturaleza dentro de los principios físicos de Aristóteles, Zabarella recurre a Averroes para explicar que en ella concurren formas imperfectas que al unirse producen una nueva forma ${ }^{34}$. Ambos son coincidentes en la consideración de que la verdadera causa del calor en el mundo es el cielo y no el fuego, que concurre simplemente como instrumento pasivo ${ }^{35}$. Importante es igualmente el hecho de que Zabarella acoja desde la tradición averroísta la opinión de que en los seres vivos hay una pluralidad de almas distintas en especie para explicar la pluralidad de facultades vitales que se observan ${ }^{36}$. $\mathrm{O}$ el hecho de que ambos coincidan plenamente en la consideración de las especies inteligibles ${ }^{37}$.

Zabarella, en efecto, defiende a Averroes de las interpretaciones que él considera erradas y que pueden llegar de fuera de las filas de los averroístas o de éstos mismos. De hecho, en numerosas ocasiones Zabarella critica a los averroistae pero exonera a Averroes. Cabe decirse incluso que en la mayoría de las veces en las que él se refiere a éstos lo hace en unos tonos críticos que contrastan abiertamente con el respecto y la adhesión que siente por Averroes. Esta actitud, que ya está presente en las obras lógicas ${ }^{38}$, es muy patente en el De rebus naturalibus, en donde la consideración de Averroes como el gran intérprete de Aristóteles se fundamente en gran medida en el "rescate" de su verdadero sentido, de tal manera que en ambos casos, es decir, en la recuperación tanto del Aristóteles fidedigno, como en la del Averroes fidedigno, la postura de Zabarella es muy semejante: Aristóteles fue correctamente interpretado por Averroes si entendemos bien a Aristóteles y si entendemos bien a Averroes.

Ante el peso que el pensamiento de Averroes tiene en Zabarella, y concretamente hablando, en el De rebus naturalibus, la cuestión que cabe plantearse es la de si es posible aplicarle simplemente el apelativo de averroísta. El tema tiene, sin duda, sus dificultades. Como señala William F. Edwards en un artículo precisamente titulado "The Averroism of Iacopo Zabarella" 39 , comúnmente se ha considerado que para que un autor sea realmente averroísta debe cumplir con un triple requisito: a) debe sostener la unidad del intelecto, en el sentido de que éste es una entidad separada, independiente del hombre, única e inmortal que en algún momento de su desarrollo

\footnotetext{
Zabarella $D R N$, X, cap. cap. 6, pág. 266-267.

Zabarella $D R N$, XIII, cap. cap. 7, pág. 320-321.

Zabarella DRN, XVII, cap. 11, pág. 404.

Zabarella $D R N$, XXI, cap. 8, pág. 490.

Zabarella $D R N$, XXVIII, cap. 5, pág. 692.

38 Cfr. Martin 2007, p. 15, quien cita el siguiente texto del De propositionibus necessariis de Zabarella (II, 2, ed. Cologne, p. 380): "Averroes autem hac in re satis improprie locutus est, disputans quodnam sit praedicatum primum. primum enim non dicitur praedicatum, sed subiectum respectu praedicati; sed excusandus est, quia Arabs fuit, et Graecae linguae ignarus, eo praesertim, quod etsi in appellatione aliquid erroriis commisit, in re tamen ipsa non erravit: imo adeo egregie se gessit, ut nemo profundus ac melius, quam ipse, mentem Aristotelis hac in re penetravit: nam et Graecorum errores detexit, atque impugnavit, \& totam rei veritatem pulcherrime explanavit."

39 Cfr. Edwards 1960, p. 91. Véase también las interesantes reflexiones de A. Akasoy al respecto: Akasoy 2013, pp. 321-348.
} 
se une a él; b) debe sostener la eternidad del mundo en virtud de lo que Aristóteles sostiene en el libro VIII de la Física, a saber, que el movimiento ha existido eternamente; c) debe reconocer de algún modo la doble verdad cuando la teología y la filosofía entran en conflicto. Ciertamente ante estos requisitos habría que descartar categóricamente que Zabarella sea un averroísta, pues ya en el primer caso él rechaza manifiestamente en el libro XXVII la unidad del intelecto y dedica un buen número de páginas y capítulos a demostrar que la postura de Averroes es contraria a los principios de la filosofía natural de Aristóteles ${ }^{40}$. Aquí es evidente el ascendiente que Alejandro de Afrodisias tiene sobre la concepción naturalista que Zabarella formula acerca de la naturaleza de la facultad intelectiva del ser humano ${ }^{41}$. Junto a Alejandro, en efecto, sostiene que la facultad intelectiva del ser humano puede y debe ser explicada sin recurrir, en cuanto a su génesis y a su desarrollo, a ninguna entidad externa a las facultades intrínsecas del alma: para él la denominada alma intelectiva no escapaba, por tanto, a la consideración, como cualquier alma animal, de forma informante del cuerpo. No hay, dice Zabarella en su De mente humana ${ }^{42}$, señal alguna en los escritos naturales de Aristóteles que haga pensar que éste sacó el alma intelectiva fuera del ámbito sobre el que se aplica la definición general de alma que dio en el libro II del De anima. Por otro lado, en el De mente agente Zabarella explica con detenimiento que el proceso de abstracción que conduce desde la imagen sensible (potencialmente inteligible) a la forma universal en acto se realiza en el seno de las facultades psíquicas individuales. Para ello se basta el intelecto posible, puesto que - dice Zabarella- "aunque Aristóteles dijera que entender es padecer, pues en virtud de su origen es padecer y para conocer su naturaleza nos resulta más fácil nombrarlo por el padecer que por el actuar, sin embargo inteligir es también actuar. Y es que el conocimiento no consiste sólo en la recepción de las especies, que es una forma de pasividad, sino también en el juicio de las especies recibidas, que es una forma de actividad. Por lo tanto, el intelecto paciente al recibir la especie ciertamente padece, pero al juzgarla actúa, y actuando así se dice que abstrae, de ahí que se diga que la intelección es inmanente, pues es realizada por el propio intelecto paciente y por él mismo es recibida" 43 .

Así pues, por lo que a la cuestión de la unidad del intelecto se refiere Zabarella está más cerca de ser un alejandrista que un averroísta; sin embargo, no es menos cierto que, al margen de esta cuestión de la naturaleza del alma intelectiva, el peso de Alejandro de Afrodisias en el resto del De rebus naturalibus es secundaria y está a una enorme distancia del que hemos visto que tiene Averroes ${ }^{44}$.

40 Zabarella DRN, XXVII, cap. 6, p. 648: "Hanc Averrois sententiam ego et absolute secundum ipsam rei veritatem, et secundum philosophiam Aristotelis falsam esse existimo, veram autem alteram illorum qui dicunt animam rationalem humanam vere formam hominis esse qua homo est homo et in specie constituitur".

41 Cfr. Di Napoli 1963, pp. 376-379; Kessler 1988, pp. 530-534; Kessler 2011, pp. 49-58; Mitrovic 2009, pp. 330354; Valverde 20121, pp. 27-56.

42 Zabarella $D R N$, XXVII, cap. 7, p. 652.

43 Zabarella $D R N$, XXIX, cap. 7, p. 712: "Ad hoc dicimus verum quidem illud esse quod ex vi vocabuli sumitur, abstractionem esse actionem, sed negandum esse patibilis intellectus officium esse solum pati, quia licet Aristoteles dixerit intelligere esse pati, quia secundum originem est pati, et facilius ad cognoscendam eius naturam ducimur per pati quam per agere, tamen intelligere est etiam agere; nam cognoscere non in sola specierum receptione, quae passio est, consistit, sed etiam in receptarum iudicatione, quae est actio, quare patibilis intellectus speciem quidem recipiendo patitur, sed eam iudicando agit, et ita agendo dicitur abstrahere, quo fit ut intellectio dicatur actio immanens, quia fit ab ipso patibili intellectu et in ipsomet recipitur."

44 En algunas cuestiones manifiesta Zabarella su acuerdo con Alejandro de Afrodisias. Así por ejemplo, en el libro segundo (cap. 7, p. 101) Zabarella acepta la lectura que Alejandro hace de un texto del libro II de la Física en 
El ya citado Edwards ha evaluado todas estas circunstancias y ha situado la filosofía natural de Zabarella en el contexto de un aristotelismo que ya a finales del siglo XVI estaba lejos de mantener las purezas doctrinales y hermenéuticas de etapas anteriores. Para él, como para cualquiera que lea con un poco de atención los textos del filósofo paduano es patente la admiración que éste sentía por Averroes, una admiración que lo lleva a identificar su pensamiento con el de Aristóteles, y esto hasta el extremo de que su propio pensamiento, el pensamiento de Zabarella, se construye en muchas ocasiones más sobre la base de la interpretación de Averroes que sobre los propios textos interpretados ${ }^{45}$. Que en la cuestión ciertamente importante de la naturaleza del intelecto humano y en la cuestión de la inmortalidad del alma, relacionada directamente con la primera, Zabarella adopte una postura alejandrista que en esencia lo vincula con Pietro Pomponazzi o con Simone Porzio, sólo en apariencia debe entenderse como una contradicción interna en su pensamiento o como la manifestación de una fluctuación doctrinal severa. Y ello porque, durante la segunda mitad del siglo XVI el averroísmo se manifiesta en muchas ocasiones más bien en el ámbito de la lógica y la metodología que en el de la psicología ${ }^{46}$; así, algunos autores que rechazan de plano la unidad del intelecto aceptan, sin embargo, sin problemas la propia gnoseología averroísta que pone el acento en el hecho de que es el hombre el que, con sus propios instrumentos gnoseológicos, que Averroes sitúa en el terreno de la facultad imaginativa, debe construir su propio conocimiento partiendo desde una base empírica que resulta ineludible. Ésta es precisamente la consecuencia que tiene desde el punto de vista de la adquisición del conocimiento la radical separación del intelecto con respecto al hombre: "Con la separación total del intelecto con respecto al hombre, en otras palabras, venía a generarse la necesidad de edificar desde los cimientos otra vez. En las manos de Averroes y los averroístas el conocimiento se hizo más natural y humano, una empresa en la que el hombre con sus capacidades sensitiva e imaginativa -aunque se admitía su modestia, aun así se consideraban de gran potencia- podía esperar participar de nuevo. El instrumento para esta re-humanización del conocimiento fue una rigurosa conciencia naturalista del De anima, y

donde defiende que la privación no puede ser considerada una forma, de modo que no puede constituirse en la esencia de la materia prima. Igualmente en el libro III (cap. 18, p. 149) Zabarella acude a Alejandro para sostener su teoría (afín igualmente a Averroes y contraria a Tomás) de que la materia está dotada de una cantidad indeterminada. Finalmente, en el libro VI (cap. 11, p. 199) Zabarella acepta la doctrina de Alejandro para señalar que en el cielo no hay forma y materia, sino materia dotada de una naturaleza predeterminada, y el alma es para ella un principio motor externo, no su naturaleza.

45 Cfr. Edwards 1960, p. 95: "Es, en efecto, imposible leer a Zabarella sin concluir que su admiración por Averroes sobrepasaba todos los límites, y que incluso el Filósofo en el pensamiento de Zabarella jugaba un papel en cierta forma de segunda fila." De hecho, hay en el $D R N$ un momento bien identificable en el que Zabarella reconoce que para explicar un hecho concreto debe desprenderse de la explicación de Aristóteles, que es insatisfactoria, y debe acudir directamente a Averroes. En el libro XVII, «De calore caelesti», trata Zabarella una difícil cuestión: el calentamiento de la esfera sublunar se produce por el movimiento de fricción que genera la esfera superior en su rotación. Por otro lado, Aristóteles señalaba que era la esfera del Sol la que producía el calentamiento, pues posee la velocidad suficiente para generar ese calor; sin embargo, es evidente que entre la esfera del Sol y la de la Tierra se encuentra la de la Luna, por lo que hay que preguntarse cómo es posible que, si el calentamiento se produce por fricción, sea el Sol, y no la Luna, cuyo movimiento -sostenían los aristotélicos-es más lento, el que produce ese calor en la tierra. Ante esta difícil aporía Zabarella no tiene inconveniente en reconocer su incapacidad para salvarle la cara a Aristóteles, por ello quiere hablar por sí mismo y va a dejar a un lado a Aristóteles. Él considera, en efecto, que si se obvia lo que el Estagirita expresamente señaló, la respuesta más razonable es la que dio Averroes: defendía que lo que mueve la esfera sublunar y produce el calor no es sólo la esfera adyacente a ella, sino toda la profundidad de las esferas superiores como un cuerpo único (DRN, XVII, cap. 6, p. 396).

46 Cfr. Edwards 1960, p. 101. 
a lo largo del siglo XVI la tarea se había completado en su totalidad. Desde la gran tradición de comentario y controversia había emergido una teoría del conocimiento sistemática y elaborada al detalle, hábilmente vinculada con la teoría del método establecida a lo largo de los Analíticos Posteriores, y finalmente adaptada a las necesidades de la ciencia de la época. Es esta teoría del conocimiento la que encuentra su expresión final en los trabajos de Zabarella"47. Esta radical distinción del orden ontológico del ser humano con respecto al de las inteligencias superiores remite, en última instancia, a ese proceso de re-humanización del conocimiento que en Zabarella es expresión del hecho de que el procedimiento de adquisición del conocimiento, esto es, el método, se desvincule del estudio natural de la psicología y se sitúe en la voluntad y la libre decisión del individuo ${ }^{48}$.

Por otro lado, más allá de esta vinculación metodológica entre Zabarella y la tradición averroísta de la que habló Edwards, no cabe duda de que, como hemos dicho, Zabarella tenía en altísima estima la vertiente propiamente hermenéutica de Averroes. Ciertamente no hizo mella en él, como por otro lado tampoco en otros muchos aristotélicos, la caricaturización que se hizo desde las filas de algunos humanistas de los Averroistae como gente bárbara, carente de elegancia discursiva e incapaz de articular un latín mínimamente digno. Zabarella, en efecto, era gran conocedor del griego y en general de las fuentes clásicas, conocía y leía en su lengua a Alejandro, Temistio, Simplicio y Filopón, entre otros, y aun reconociendo su maestría en ciertas cuestiones naturales, lo cierto y verdad es que se decantó casi siempre por Averroes $^{49}$. Cabe pensar, pues, que, al menos en tiempos de Zabarella, esa dicotomía entre humanismo y averroísmo no estaba presente. En este sentido, se ha insistido por parte de importantes figuras de la historiografía moderna ${ }^{50}$ en que el aristotelismo experimentó un proceso de asimilación e incorporación de los cánones humanistas; este proceso afectó a todas las corrientes que se inscribían dentro de él y a todos los autores, también a aquellos que, como Zabarella, ponían sus ojos en Averroes como el depositario de la más acertada interpretación de los textos aristotélicos. Una prue-

47 Edwards 1960, p. 100.

48 Éste es el núcleo del famoso debate que se estableció entre Francesco Piccolomini y Giacomo Zabarella en la Universidad de Padua. Efectivamente, Zabarella en todos sus escritos lógicos había tratado la lógica no como una ciencia sino como una fuente del método, el cual por otro lado sólo tenía para él vis notificandae, es decir, no era más que un procedimiento para hacernos a nosotros mismos, dadas las características de nuestras capacidades intelectuales, las cosas más claras. Por otro lado, Zabarella distinguía dentro del término genérico methodus lo que es el methodus sensu strictu y lo que es el ordo. En el primer caso estamos hablando del procedimiento por el que se avanza de lo conocido a lo desconocido, mientras que en el segundo caso el ordo es sencillamente la organización expositiva de lo conocido, y está vinculada estrechamente a la enseñanza. Pues bien, precisamente en el De methodis (I, cap. 8) Zabarella subraya que el verdadero motivo por el que se constituye un ordo doctrinae (tal y como el que está expuesto en el primer libro del De rebus naturalibus) es el conocimiento distinto de la realidad más que la realidad misma, por lo que se trata más bien de un procedimiento basado en la voluntad y no en la constitución ontológica del mundo. Esta concepción fue severamente criticada por Francesco Piccolomini en 1583 con la publicación de su obra Universa philosophia de moribus: se trataba de un denso escrito, dedicado la Senado veneciano, que se presentaba como un curso de educación para nobles destinados a desempeñar funciones en la alta política. Uno de los tópicos centrales de la obra es lo que Piccolomini denominaba la «constitución divina del ordo», y ataca a Zabarella señalando precisamente que el ordo doctrinae debe fundamentarse en la propia realidad de las cosas, y por ello debe estar subordinado más bien a la metafísica que a la lógica: para sustentar esta concepción Piccolomini aportaba argumentos tomados del propio orden expositivo que se encuentra en la obra de Aristóteles. Cfr. Jardine 1997, pp. 183-209.

49 Cfr. Poppi 19722, p. 19.

50 Véase, por ejemplo, Garin 1947, pp. 55-104; Poppi 19701, pp. 13-47; Kristeller 1979, pp. 85-105; Schmitt 1983, pp. 17-19; Copenhaver 1988, p. 77; Bianchi 2003, pp. 148-160. 
ba de esto es el gran número de ediciones que se realizaron de las obras de Averroes en la segunda mitad del siglo XVI, y concretamente la gran edición de la obra de Aristóteles acompañada de la de Averroes que se gestó en Venecia en ocho volúmenes y tres suplementos: aquí sin ir más lejos se realizó un ingente esfuerzo filológico que supuso, entre otras cosas, la aparición de los textos latinos de Aristóteles en varias versiones simultáneas ${ }^{51}$. En esta corriente de reedición y reinterpretación tanto de Aristóteles como de Averroes hay que situar, sin duda, la figura de Zabarella.

En el De rebus naturalibus puede hallarse, pues, un catálogo de autoridades amplísimo que recorre toda la tradición peripatética antigua, medieval y renacentista. Ahora bien, cabe preguntarse aquí también por la visión que Zabarella tiene de las otras grandes tradiciones en lo que se refiere a la filosofía natural. En este sentido, hay que subrayar la gran presencia de Platón y de Plotino, cuyos pareceres en algunas cuestiones son escrutados por Zabarella y no es infrecuente que lo haga con un signo de aprobación ${ }^{52}$. Igualmente presente está Galeno en un sinfín de referencias que están presentes no sólo en los libros de carácter más "biológico" del De rebus naturalibus, sino también en los otros. En todo caso, él expresa con toda claridad la superioridad del aristotelismo en todo lo que se refiere a la ciencia natural, de modo que quien quiere acercarse a la verdad en este terreno no debe buscar otra autoridad: ni el Timeo de Platón, ni mucho menos las obras de Galeno o de Avicena se le acer$\operatorname{can}^{53}$. Sin embargo, la actitud que tiene Zabarella con respecto a las otras corrientes es muy distinta. No puede decirse, en efecto, que él concibiera propiamente el platonismo como un pensamiento rival desde el punto de vista del estudio de la naturaleza. Lo tiene más bien como un precursor del aristotelismo o como una expresión menos desarrollada del mismo pensamiento naturalista que terminaría eclosionando en la propia tradición peripatética. Algo, en todo caso, muy lejano de la severa crítica y del rechazo que Zabarella expresa siempre que tiene ocasión hacia Galeno y sus huestes. Aquí sí que identifica una verdadera corriente de filosofía natural rival del aristotelismo. Los tonos de desprecio y la catalogación de los seguidores de Galeno, a los que él engloba frecuentemente bajo el apelativo de medici, el cual tiene en su discurso un sentido claramente peyorativo, como una subespecie de filósofos naturales, no dejan de revelar que Zabarella tenía gran interés en marcar el territorio y en distinguir netamente el discurso aristotélico del galénico.

Esta actitud, por lo demás, no es ni mucho menos exclusiva del filósofo paduano; al contrario, hay que tener en cuenta que, como J. H. Randall ya puso de manifiesto

51 Cfr. Schmitt 1983, pp. 54-56.

52 Hay que señalar que, por ejemplo, Zabarella considera que el Símil del Sol que Platón formuló en el libro VI de la República es interpretable en los términos en que él interpretó el intelecto agente, es decir, identificándolo con Dios: cfr. $D R N$, XXIX, cap. 13, p. 721. Por otro lado, a Plotino acude Zabarella en no pocas ocasiones con tonos críticos a veces, pero en otras como una auténtica autoridad que le sirve de apoyo ante determinadas cuestiones. Así, por ejemplo, en la consideración de la materia como una entidad potencial Plotino es alabado y su pensamiento es aceptado en contra del criterio de Scoto (DRN, III, cap. 4, p. 127; y más tarde (cap. 18, pp. 148-149), cuando se sostiene que la materia está dotada de una cantidad interminata, Zabarella vuelve a elogiar el buen criterio de Plotino.

53 Zabarella $D R N$, I, cap. 1, p. 1: "Tradidere quidem eam scientiam priscis temporibus complures, sed in eo munere ita excelluisse creditur Aristoteles, ut nemo in hac philosophiae parte non modo illi praeferendus, sed ne comparandus quidem cum eo esse videatur, quod quidem omnium et antiquorum et posteriorum ad haec usque tempora philosophorum consensio comprobavit. Tot enim viri praeclarissimi et Graeci, et Latini, et Arabes in interpretandis naturalibus Aristotelis libris aetatem consumpserunt, ut cognovisse omnis posteritas videatur non posse ab humano ingenio excellentius tradi naturalem philosophiam, siquidem tantum honoris neque naturalibus Avicennae aut Galeni libris, neque magni Platonis Timaeo habitum esse certum est”. 
en su histórico tratado acerca del método científico en la Universidad de Padua $^{54}$, en este ámbito se habían congregado a lo largo del siglo XVI una serie de figuras, como Nicolò Leoniceno, Giovanni Manardi, Giovan Battista Da Monte etc., los cuales, habiendo destacado como médicos, habían dejado obras sobre metodología que trataban de desarrollar los presupuestos que Galeno había formulado en el Proemio de su Ars medica. Es claro que Zabarella empuñó su pluma y escribió el De methodis en gran parte contra estos galenistas que, además de negar la supremacía lógica de Averroes, y por tanto de Aristóteles, contendieron fuertemente en el ámbito de la fisiología con los aristotélicos. Así por ejemplo, ellos sostenían, siguiendo a Galeno y atacando particularmente a Averroes con un gran arsenal de argumentos, que el órgano principal no es el corazón sino el cerebro.

Este contencioso se desarrolló y se enconó a lo largo de la segunda mitad del siglo $\mathrm{XVI}$; de este modo la verdadera rivalidad no se encontraba ya en las propias filas del aristotelismo entre averroístas y alejandristas, cuyos postulados o al menos una parte de ellos podían confluir en un mismo autor, como es el caso de Zabarella, sino entre aristotelismo y galenismo ${ }^{55}$. Los aristotélicos percibieron el desarrollo que la metodología estaba teniendo entre las filas de los galenistas, como consecuencia del enorme desarrollo que estaba experimentando su ciencia, como una grave amenaza a la hegemonía que ellos habían tenido hasta ese momento. No hay que olvidar que aquellos medici a los que peripatéticos como Zabarella se referían con un deje de desprecio habían sido compañeros suyos en las aulas universitarias, habían estudiado como ellos lógica y filosofía natural, y estaban perfectamente capacitados para adentrarse en el terreno de la metodología científica y en el de la propia filosofía natural para formular teorías y explicar la estructura, por ejemplo, del cuerpo vivo de un modo alternativo al estrictamente aristotélico.

En el De rebus naturalibus no cuesta ver esta tensión entre aristotelismo y galenismo. Como cabe esperar, aquí la discusión no está en el terreno de la lógica sino en el de la filosofía natural. En este ámbito, Zabarella se detiene con gusto a contradecir a Galeno en diversas cuestiones. Un buen ejemplo de esto lo encontramos en el libro XX, el tercero de los que dedica al tema de la generación y la corrupción, y que está destinado únicamente a analizar la definición que Galeno dio de la corrupción en el De methodo medendi ${ }^{56}$ y a refutar a todos aquellos philosophi et medici que establecieron que esa definición ("putrefactio est mutatio ad corruptelam totius substantiae putrescentis ab externa caliditate") viene a ser la misma que la que Aristóteles propuso en el libro IV de los Meteorologica ("Putrefactio autem est corruptio eius, quae in unoquoque humido proprie, et secundum naturam caliditatis, ab aliena caliditate. Haec autem est, quae ambientis") ${ }^{57}$. Con gran fruición, Zabarella trata de distinguir lo que dijo Galeno de lo que dijo Aristóteles destacando que la definición del primero es imperfecta y lógicamente mal formada, y ello porque esa definición es aplicable a otras cosas además de a la corrupción propiamente dicha: igualmente es aplicable a la combustión, pues la combustión es también una mutación completa de una substancia por efecto de un calor externo excesivo. Además, hay otro error en la definición de Galeno: éste no habló del sujeto, es decir, no le asignó a la corrupción

\footnotetext{
Cfr. Randall 1961, pp. 177-206.

Cfr. Kessler 2011, pp. 52-53.

Galenus 1821, X: De methodo medendi, p. 753.

Aristóteles, Meteorologica, IV.1, 379a16-18 (Aristóteles 1562, V: Meteor., lib. IV, t/c 6, f. 468vL).
} 
ningún sujeto propio, sino que habló de toda substancia corpórea, mientras que Aristóteles con aquel in unoquoque humido de su definición se refería precisamente a todo cuerpo mixto y húmedo, pues todo lo que es tal está sometido a la putrefacción. Y es que, según Zabarella, Galeno no habla en su definición de la verdadera esencia de la putrefacción, que es la corrupción del calor interno por efecto del calor ambiental: él, en efecto, hablaba de la causa remota, ese calor externo, pero nada decía de la causa intermedia, el calor natural; sin embargo, sin el efecto intermedio no se puede conocer la naturaleza real de la putrefacción ${ }^{58}$.

Ante estas evidencias Zabarella rechaza como absurda y contradictoria la tarea de todos aquellos que habían tratado de perfilar la definición de Galeno para hacerla afín a la de Aristóteles: no hay para él, en efecto, posibilidad de homologación entre una definición deficientemente concebida y otra que cumple perfectamente con los criterios lógicos que son exigibles a una definición rigurosa, los cuales ya fueron establecidos por Zabarella precisamente en el De methodis, que, como hemos visto, tenía como fin socavar los postulados metodológicos que desde las filas del galenismo se habían establecido.

Este mismo afán de distinguir con absoluta nitidez el ámbito del aristotelismo del ámbito del galenismo lo vemos reflejado también en otras cuestiones más específicamente vinculadas con la fisiología. Así, por ejemplo, Zabarella rechaza abiertamente la explicación que da Galeno de las funciones de los órganos principales, y en concreto de la primacía por él atribuida al cerebro y al hígado. Para aquél es insostenible que el hígado o el cerebro puedan tener en modo alguno la primacía entre los órganos corporales. En el caso del primero no puede ser, pues el hígado en el proceso de la alimentación sólo prepara la materia alimenticia; la verdadera transformación la realiza el calor natural, que es enviado por el corazón a todas las partes: por lo tanto, el corazón es el agente primario de la alimentación. Por otro lado, se observa que el cerebro es más frío que las otras partes, como el propio Galeno reconocía, luego no puede ser el asiento del alma, que es propiamente fuente de calor natural. Por ello el cerebro es un instrumento secundario del alma, el cual recibe su poder de los espíritus enviados por el corazón. La función del cerebro es refrigerar los espíritus que proceden del corazón y hacerlos aptos para el conocimiento, ya que éste requiere tranquilidad y reposo, y el calor produce justo lo contrario ${ }^{59}$.

\section{Método empírico y distinción lógica: la originalidad del discurso expositivo de Zabarella}

Anteriormente hemos hablado de que el desarrollo de los argumentos que Zabarella expone en el De rebus naturalibus responde a unas cuantas pautas identificables. Acabamos de dedicar algunos párrafos a la primera, es decir, al continuo diálogo crítico que el filósofo paduano tiene con toda la tradición. Ahora queremos dedicar algunas líneas a estudiar las características más significativas del modelo explicativo de Zabarella precisamente a partir del momento en que, debatidos otros puntos de vista, pasa a exponer el suyo. Aquí podríamos destacar varios elementos. Efectivamente, ya hemos tenido oportunidad de decir algo acerca de la presencia que tiene 
la experiencia en el discurso de Zabarella y el peso que le da. Como criterio metodológico la experiencia es para él la verdadera fuente del conocimiento; no hay por lo tanto para el físico más camino que el de la observación para entender cómo la naturaleza ha constituido las cosas: "sunt enim a philosopho naturali cognoscendae res naturales ut sunt a natura constitutae" ${ }^{\prime 60}$. Ahora bien, es cierto que a la hora de esgrimir su propia explicación sobre un asunto concreto, Zabarella suele acudir a la experiencia bien sea para contradecir otras explicaciones, bien sea para determinar cómo deben entenderse aquellos puntos en los que el discurso de Aristóteles y la experiencia común parecen entrar en conflicto. No hay en Zabarella una construcción teórica que parta sistemáticamente de la experiencia adquirida ni mucho menos que elabore un andamiaje experimental para comprobar la validez de sus explicaciones ${ }^{61}$. Cuando, como hemos dicho, la explicación que da Aristóteles a un hecho entra en contradicción con la experiencia, Zabarella casi siempre se decanta por hacer un ejercicio de distinctio mediante el cual intenta extraer matices del propio discurso del maestro que le permitan acomodarse con la experiencia.

En varios lugares es patente este ejercicio de Zabarella. Pongamos aquí un ejemplo. En el libro XIV el autor aborda el tema de las cualidades primarias y su funcionalidad en la constitución de los cuerpos mixtos. Según Aristóteles ${ }^{62}$, de las cualidades primarias unas tienen una funcionalidad activa -el calor y el frío-, y otras un papel meramente pasivo - la humedad y la sequedad-. Por su parte, el calor congrega lo homogéneo y segrega lo heterogéneo, mientras que el frío congrega tanto lo homogéneo como lo heterogéneo. La humedad es aquello que no tiene unos límites fijos y es fácilmente delimitable, en cambio lo seco es lo que tiene unos límites fijos y es difícilmente delimitable. A raíz de estas definiciones surge un gran número de dificultades que tienen que ver precisamente con lo que experimentamos cotidianamente: el calor también hace que cosas heterogéneas, al calentarse juntas, se unan de tal manera que ya no puedan separarse nunca más; experimentamos que el frío en invierno hace que los ojos lagrimeen, luego hace que se segreguen cosas heterogéneas; con respecto a la definición de lo seco vemos que lo contrario ocurre con el fuego, que es sumamente seco y es fácilmente delimitable. Pues bien, para salvar estos desajustes entre la definición de Aristóteles y la experiencia Zabarella establece la siguiente distinción: efectivamente, de la universalidad de la definición de Aristóteles no hay ninguna duda, pero hay que tener en cuenta que puede algo competirle a una cosa esencialmente y por accidente competirle lo contrario. Esto -dice Zabarella- ocurre en razón de conveniencia y similitud natural ${ }^{63}$. Por ejemplo: en el caso concretamente del calor, pueden a él competirle algunas cosas por su propia naturale$\mathrm{za}$, mientras que algunas otras le competen como agente instrumental de otro agente primario: el calor en la sangre es un instrumento del alma, que hace las funciones de agente primario, por ello puede ese calor congregar en las venas cosas heterogéneas.

En otras ocasiones, sin embargo, Zabarella elude distinciones y sutilezas y se decanta por aquellas razones que ofrecen la explicación más simple de un fenómeno determinado. Un caso de esto lo podemos encontrar en el libro XVII, dedicado a la cuestión de la naturaleza del calor celeste. Aquí se aborda un tema que ha suscitado

\footnotetext{
Zabarella DRN, XIV, cap. 7, p. 348.

Cfr. Schmitt 1969, pp. 80-138.

Cfr. Aristoteles, De generatione et corruptione, II.2, 329b30-330a7; De partibus animalium, II.1, 646a15-20.

Zabarella DRN, XIV, cap. 4, p. 339.
} 
un gran debate en el seno del aristotelismo. En el libro segundo del De generatione animalium Aristóteles parece establecer una distinción entre el calor celeste, inserto en el esperma y generador de vida, y el calor elemental del fuego, el cual no es constitutivo de vida, sino más bien lo contrario ${ }^{64}$. Ante esta distinción se ha planteado la duda de si Aristóteles habla aquí de dos tipos de calor esencialmente diferentes entre sí, y de hecho así ha sido sostenido por la mayor parte de los aristotélicos. Zabarella, por el contrario, prefiere sostener que no hay en la Tierra dos calores, sino uno solo, el cual puede hacer que aparezca la forma del elemento o la forma del compuesto imperfecto, y por ello lo llamó Aristóteles "calor elemental", o puede hacer que se genere un ser vivo y por ello lo denomina "calor celeste" por analogía con el calor etéreo. La diferencia no está, pues en el calor en sí, sino en aquello que el fuego hace y cómo lo hace, pues puede actuar por sí mismo (en los elementos), o puede ser utilizado por un agente superior, por ejemplo, el alma. Pero en todo caso hace lo mismo: rarefactio y atteritio ${ }^{65}$.

Otro ejemplo de búsqueda de la explicación más sencilla lo encontramos en el libro XIX, en donde Zabarella sostiene la existencia de un sólo tipo de putrefacción natural, no dos tipos como habían sostenido anteriormente otros ${ }^{66}$.

Finalmente, en otras ocasiones - muy numerosas, por otro lado-Zabarella construye su propia posición como un punto intermedio entre dos posiciones extremas. Un ejemplo, entre los muchos que se pueden elegir ${ }^{67}$, lo encontramos en el libro XXII, en donde estudia, entre otras cuestiones relacionadas con las distintas funciones del alma, el peliagudo tema de la ubicación del alma en el cuerpo. Para Zabarella hay que encontrar la verdad de este tema en un equilibrio entre la opinión de Tomás, que sostenía que el alma, como substancia simple e indivisible que es, está en cualquier parte del cuerpo, no sólo en el miembro principal, y la de Alberto, para el que el alma sólo tiene una sede, y ésa es el corazón. El equilibrio, según Zabarella, se halla en el hecho de que la opinión de Alberto no sea desdeñable en su totalidad: en efecto, él acertó al establecer el primado del corazón entre los demás órganos vitales como sede del alma, y ello porque es manifiesto que Aristóteles sostenía esta concepción, de modo que es razonable sostener que el alma reside de manera principal y permanente en el corazón, y en él está como en su raíz, a partir de la cual se difunde la substancia del alma a las demás partes: de ahí que lo primero que se genere en un animal sea el corazón. Las demás partes tienen, pues, el alma por participación, y para ilustrar esto se echa mano del símil del Sol y la luz en el mundo: todas las cosas tienen el ser por participación del primer ente, el cual posee el ser por sí. Por esta razón, si la mano se separa del cuerpo, se extingue de inmediato su vida, pues la mano no tiene vida sino por el continuo flujo de vida que proviene del corazón. En el caso de las plantas y de los insectos anulosos, en vez de corazón, lo que hay es un humor que se extiende por todo el cuerpo y posee por sí mismo el principio vital ${ }^{68}$.

\footnotetext{
64 Aristoteles, De generatione animalium, II.3, 736b30-7.

65 Zabarella $D R N$, XVII, cap. 11, pp. 403-404.

66 Zabarella $D R N$, XIX, cap. 12, p. 446.

67 Ejemplos de explicaciones que suponen un término medio entre dos teorías rivales los podemos encontrar en $D R N$, XVIII, cap. 9, pp. 419-420; XIX, cap. 16, p. 456; XX, cap. 4, p. 484.

68 Zabarella $D R N$, XXII, cap. 5, p. 513-514.
} 


\section{Conclusión}

Todas estas características del discurso de Zabarella están puestas al servicio de ofrecer una visión coherente y sistemática del aristotelismo: la diversidad de opiniones internas y las objeciones que se puedan plantear intra o extramuros pretenden ser superadas con un análisis profundo de los problemas interpretativos de los escritos de Aristóteles y de las soluciones que se han dado a lo largo de la historia. El De rebus naturalibus es, por el mérito de Zabarella a la hora de localizar esos problemas y agotar sus trayectorias por la larga tradición peripatética, aún hoy una magnífica herramienta que la historiografía moderna tiene a su disposición. En sus numerosas páginas los historiadores de la filosofía pueden estudiar cómo el aristotelismo, justo cuando empezaba a periclitar, hacía ingentes esfuerzos para lograr la coherencia sistemática que su propia base textual, la obra de Aristóteles, tanto obstaculizaba. Precisamente por eso la búsqueda de esa coherencia exigía enormes esfuerzos interpretativos y un ingente caudal de referencias históricas cuya finalidad era ofrecer una especie de síntesis universal de la filosofía natural. Con esta síntesis autores como Zabarella y otros coetáneos ${ }^{69}$ suyos no pretendían sino solventar la diversidad y la dispersión que la física aristotélica contenía después de tantos siglos de incuestionada vigencia.

A la vista de la trayectoria de la filosofía en los siglos sucesivos resultará ridículo preguntarse si un Pomponazzi, un Zimara, un Zabarella o un Cremonini, por poner algunos ejemplos, tuvieron éxito a la hora de revivificar el aristotelismo en el ámbito de la filosofía natural. En todo caso, se hace evidente ante la magnitud de sus obras que la tarea de dar unidad al enorme aluvión de materiales que la historia del aristotelismo había acumulado era una tarea imposible. El legado de sus obras muestra hoy que la crisis del aristotelismo se debió tanto a causas externas (es decir, la nueva concepción heliocéntrica) como a causas internas. Entre estas últimas puede señalarse esa hipertrofia que impedía abordar las cuestiones desde una perspectiva puramente analítica y que obligaba siempre a hacer enormes excursos histórico para solucionar los problemas que nacían de las propias dificultades interpretativas de la obra de Aristóteles. En este sentido, las propias exigencias textuales que había traído el humanismo al aristotelismo y que hicieron que los propios aristotélicos dominaran el griego clásico y leyeran los textos de Aristóteles en la lengua en que fueron escritos, no hicieron que amainaran los debates, sino más bien lo contrario. Las dificultades textuales se manifestaron con una fuerza inédita y obligaron a gastar ingentes energías en salvarle la cara a Aristóteles (o a Averroes, como hemos visto en Zabarella). Porque ese aparato de distinciones, mediaciones, síntesis y otras sutilezas hermenéuticas que contemplamos en el filósofo paduano, y que es análogo al que se daba en otros muchos colegas suyos, pone en evidencia con gran claridad que cada vez los aristotélicos tenían más dificultades en cohesionar el material teórico heredado. Este hecho, como Luca Bianchi ha expresado con gran claridad ${ }^{70}$, se vio robustecido por el colosal esfuerzo editorial que permitió el acceso inmediato a una tradición exegética que se había ido conformando a lo largo de los siglos desde la Antigüedad hasta el Renacimiento. Los nuevos aristotélicos, especialmente de la segunda mitad del siglo XVI, pudieron confrontar todas las lecturas que se habían hecho de la obra

\footnotetext{
Cfr. Wallace 1988, pp. 225-231; Schmitt 1988, pp. 792-804.

Cfr. Bianchi 2003, p. 145.
} 
de Aristóteles, de modo que en ellos pudieron interactuar un Alejandro de Afrodisias, un Averroes, un Alberto o un Nifo: todos estos autores, y muchos otros, fueron revivificados en los textos. Esto, que en sí puede parecer un logro histórico de los aristotélicos tardorrenacentistas, generó un enmarañamiento hermenéutico de inauditas proporciones e hizo imposible una exposición asequible de las distintas partes de la filosofía aristotélica.

\section{BIBLIOGRAFÍA}

Akasoy 2013: A. Akasoy, "Was Ibn Rushd an Averroist? The Problem, the Debate, and Its Philosophical Implications", en A. Akasoy-G. Giglioni (eds.), Renaissance Averroism and Its Aftermath: Arabic Philosophy in Early Modern Europe, LondresNueva York.

Baroncini 1992: G. Baroncini, "L'articolazione del discorso empirico nella filosofia naturale di G. Zabarella, en Id., Forme di esperienza e rivoluzione scientifica, Florencia.

Bayle 1820: P. Bayle, Dictionnaire Historique et Critique, XV, Paris.

Bianchi 2003: L. Bianchi, "Una caduta senza declino? Considerazioni sulla crisi dell'aristotelismo fra Rinascimento ed età moderna, en L. Bianchi, Studi sull'aristotelismo del Rinascimento, Padua, pp. 133-172.

Biard 2005: Joël Biard, "Tradition et innovation dans les commentaires de la Physique: 1'exemple de Jacques Zabarella," en La transmission des savoirs au Moyen Âge et à la Renaissance, vol. 2 (Alfredo Perifano ed.) Besancon-Paris, pp. 289-300.

Bouillon 1999: D. Bouillon, "Un discours inédit de Iacopo Zabarella préliminaire à l'exposition de la 'Physique' d'Aristote (Padoue 1568)," en Atti e Memorie dell'Accadema Galileiana di Scienze, Letter ed Arti in Padova, 111(3), pp. 119-127.

Bouillon 2009: D. Bouillon, L'interprétation de Jacques Zabarella le Philosophe, Paris.

Cassirer 1906: E. Cassirer, Das Erkenntnisproblem in der Philosophie und Wissenschaft der neueren Zeit, I, Berlin.

Claessens 2012: G. Claessens, "Francesco Piccolomini on Prime Matter and Extension," en Vivarium, 50, pp. 225-244.

Craig 2011: M. Craig, Renaissance Meteorology: Pomponazzi to Descartes, Baltimore.

Cranz 1976: E. Cranz, "The Renaissance Reading of the De anima," en Platon et Aristote à la Renaissance: XVI Colloque international de Tours, Paris, pp. 359-376.

Dal Pra 1966: M. Dal Pra, "Una oratio programmatica di G. Zabarella [Padua 1585: MS Milano BAmbr. D.48i.inf. (xvi), fs. 1-4]," en Rivista critica di storia della filosofia, 21, pp. 286-290.

De Bellis 1997: E. De Bellis, Il pensiero logico di Agostino Nifo, Lecce.

Di Napoli 1963: G. Di Napoli, L'immortalità dell'anima nel Rinascimento, Turin.

Edwards 1960: W. F. Edwards, "The Averroism of Jacopo Zabarella (1533-1589)," en Aristotelismo padovano e filosofia aristotelica, Florence, 1960, pp. 91-107.

Edwards 1960: W. F. Edwards, The Logic of Jacopo Zabarella (1533-1589) (diss. Columbia University, New York.

Edwards 1967: W. F. Edwards, "Randall on the Development of Scientific Method in the School of Padua: a Continuing Reappraisal," en Naturalism and Historical Understanding: Essays on the Philosophy of John Herman Randall, Jr., New York.

Edwards 1969': W. F. Edwards, “A Note on Galileo's Poem, Against the Aristotelians,” en Telos, 4. 
Edwards 19692: W. F. Edwards, “Jacopo Zabarella: a Renaissance Aristotelian's View of Rhetoric and Poetry and Their Relation to Philosophy," en Arts libéraux et philosophie au moyen âge: Actes du IV Congrès international de philosophie médiévale, Montreal 1967, Montreal-Paris, pp. 843-854.

Gilbert 1960: N. W. Gilbert, Renaissance Concepts of Method, New York.

Gilbert 1963: N. W. Gilbert, "Galileo and the School of Padua," en Journal of the History of Philosophy, 1, pp. 223-231.

Gilbert 1967: N. Gilbert, "Renaissance Aristotelianism and Its Fate: Some Observations and Problems", en Naturalism and Historical Understanding: Essays on the Philosophy of John Herman Randall Jr., New York.

Imperialis 1640: I. Imperialis, Musaeum historicum et physicum, Venetiis, apud Iunctas.

Jardine 1976: N. Jardine, "Galileo's Road to Truth and the Demonstrative Regress," en Studies in the History and Philosophy of Science, 7, pp. 277-318.

Jardine 1988: N. Jardine, "Epistemology of the Sciences," en The Cambridge History of Renaissance Philosophy, (C. B. Schmitt, et al. eds.), Cambridge, pp. 685-711.

Jardine 1997: N. Jardine, "Keeping Order in the School of Padua: Jacopo Zabarella and Francesco Piccolomini on the Offices of Philosophy," en Method and Order in Renaissance Philosophy of Nature. The Aristotle Commentary Tradition, (D. Di Liscia, E. Kessler and C. Methuen, eds.), Aldershot, pp. 183-209.

Jardine 2000: "Epistemology of the Sciences", en The Cambridge History of Renaissance Philosophy, (C. B. Schmitt, et al. eds.), Cambridge, pp. 685-712.

Kessler 1988: E. Kessler, "The Intellective Soul," en The Cambridge History of Renaissance Philosophy, (C. B. Schmitt, et al. eds.), Cambridge, pp. 485-534.

Kessler 1998: E. Kessler, "Zabarella, Jacopo (1533-1589)," en Routledge Encyclopedia of Philosophy, vol. 9, (E. Craig ed.), London and New York, pp. 836-839.

Kessler 2011: E. Kessler, "Alexander of Aphrodisias and his Doctrine of the Soul. 1400 Years of Lasting Significance," en Early Science and Medicine, 16, pp. 1-93.

Kneale 1962: W. and M. Kneale, The Development of Logic, Oxford.

Kristeller 1979: P. O. Kristeller, Renaissance Thought and its Sources, New York.

Kuhn 2002: H. C. Kuhn, "Chartaceous Presence, Material Impact: Works by Paduan Aristotelians in German Libraries (a Bibliometric Study)", en La presenza dell'aristotelismo padovano nella filosofia della prima modernità, (Gregorio Piaia ed.), Roma-Padua, pp. 83-122.

Kusukawa 2002: S. Kusukawa, "Meditations of Zabarella in Nortern Europe: the Preface of Johann Ludwig Hawenreuter," en La presenza dell 'aristotelismo padovano nella filosofia della prima modernità, (Gregorio Piaia ed.), Roma-Padua, pp. 199-213.

Lines 2002: D. A. Lines, Aristotle's Ethics in the Italian Renaissance (ca. 1300-1650). The Universities and the Problem of Moral Education, Leiden, Boston and Köln.

Lohr 1982: Ch. H. Lohr, "Renaissance Latin Aristotle Commentaries: Authors So-Z", en Renaissance Quarterly, 32(2), pp. 233-243.

Maclean 2002: I. Maclean: "Meditations of Zabarella in Northern Germany, 1586-1623," en La presenza dell'aristotelismo padovano nella filosofia della prima modernitá, (Gregorio Piaia ed.), Roma-Padua, pp. 173-198.

Martin 2007: C. Martin, "Rethinking Renaissance Aristotelianism," en Intellectual History Review, 17(1), pp. 3-19.

Mikkeli 1992: H. Mikkeli, An Aristotelian Response to Renaissance Humanism. Jacopo Zabarella on the Nature of Arts and Sciences, Helsinki.

Mikkeli 1997: H. Mikkeli, "The Foundation of An Autonomous Natural Philosophy: Zabarella on the Classification of Arts and Sciences," en Method and Order in Renaissance 
Philosophy of Nature. The Aristotle Commentary Tradition, (D. Di Liscia, E. Kessler and C. Methuen eds.) Aldershot, pp. 211-228.

Mikkeli 1999: H. Mikkeli, "Jacopo Zabarella (1533-1589). Ordnung und Methode der wissenschaftlichen Erkenntnis," en Philosophen der Renaissance, (P. Richard Blum ed.), Darmstadt, pp. 150-160.

Mikkeli 2002: H. Mikkeli, "Zabarella and Piccolomini in Scandinavian Countries in the Seventeenth Century," en La presenza dell-aristotelismo padovano nella filosofia della prima modernità, (G. Piaia ed.), Roma-Padova, pp. 257-272.

Mikkeli 2010: H. Mikkeli, "Jacopo Zabarella (1533-1589): The Structure and Method of Scientific Knowledge," en Philosophers of the Renaissance, (P. Richard Blum ed.), Washington D.C., pp. 181-191.

Mikkeli 2012: Mikkeli, Heikki, «Giacomo Zabarella», en The Stanford Encyclopedia of Philosophy (Winter 2012 Edition), Edward N. Zalta (ed.), URL $=<$ https://plato.stanford. edu/archives/win2012/entries/zabarella/>.

Mitrovic 2009: B. Mitrovic, "Defending Alexander of Aphrodisias in the Age of the CounterReformation: Iacopo Zabarella on the Mortality of the Soul according to Aristotle," en Archiv für Geschichte der Philosophie, 91, pp. 330-354.

Nardi 1945: B. Nardi, Sigieri di Brabante nel pensiero del Rinascimento italiano, Rome.

Nardi 1958: B. Nardi, Saggi sull'aristotelismo padovano dal secolo XIV al XVI, Florence.

Palmieri 2007: P. Palmieri, "Science and Authority in Giacomo Zabarella," en History of Science, 45, pp. 404-427.

Petersen 1921: P. Petersen, Geschichte der Aristotelischen Philosophie in Deutschland, Leipzig.

Poppi 1970': A. Poppi, Introduzione al'aristotelismo padovano, Padua.

Poppi 1970²: A. Poppi, La Struttura del sapere in Giacomo Zabarella, Padua.

Poppi 1972': A. Poppi, "L'interpretazione dell'intelletto agente nell'opera di Giacomo Zabarella," en Scritti in onore di Carlo Giacon, Padua, pp. 323-338.

Poppi 1972²: A. Poppi, La Dottrina della scienza in Giacomo Zabarella, Padua.

Poppi 1997: A. Poppi, "La struttura del discorso morale nell'opera di Iacopo Zabarella," en Antonino Poppi, L'etica del rinascimento tra Platone e Aristotele, Napoli, pp. 231.246.

Poppi 2001': A. Poppi, "Iacopo Zabarella o l'aristotelismo come scienza rigorosa," en A. Poppi, Ricerche sulla teologia e la scienza nella Scuola padovana del Cinque e Seicento, Soveria Mannelli, pp. 125-152.

Poppi 20012: A. Poppi, "Metodo e tecnica in Iacopo Zabarella," en A. Poppi, Ricerche sulla teologia e la scienza nella Scuola padovana del Cinque e Seicento, Soveria Mannelli, pp. 153-166.

Poppi 2004: A. Poppi, “Zabarella, or Aristotelianism as a Rigorous Science,” en The Impact of Aristotelianism on Modern Science, (R. Pozzo ed.), Washington D.C., pp. 35-63.

Pozzo 1998: R. Pozzo, "Res considerata and modus considerandi rem: Averroes, Aquinas, Jacopo Zabarella, and Cornelius Martini on Reduplication," en Medioevo, 24, pp. 151175.

Ragnisco 1887: P. Ragnisco, "Pietro Pomponazzi e Giacomo Zabarella nella questione dell'anima," en Atti del R. Istituto Veneto di scienze, lettere ed arti, 6. pp. 949-996

Randall 1940: J. H. Randall, "The Development of Scientific Method in the School of Padua," en Journal of the History of Ideas, 1.

Randall 1960: J. H. Randall, Aristotle, New York-London.

Randall 1961: J. H. Randall, The School of Padua and the Emergence of Modern Science, Padua. 
Renan 1852: E. Renan, Averroès et l'Averroisme, Paris.

Risse 1964: W. Risse, “Averroismo e alessandrinismo nella logica del Rinascimento,” en Filosofia, 15, pp. 15-30.

Rossi 1983: P. Rossi, “Aristotelici e 'moderni': le ipotesi e la natura," en Aristotelismo veneto e scienza moderna, (ed. L. Olivieri), Padua, pp. 125-154.

Saitta 1950: G. Saitta, Il pensiero italiano nell'Umanesimo e nel Rinascimento, II: Il Rinascimento, Bologna.

Schmitt 1969: C. B. Schmitt, "Experience and Experiment: a Comparison of Zabarella's View with Galileo's in De motu”, en Studies en the Renaissance, 16, pp. 80-138.

Schmitt 1971: C. B. Schmitt, A Critical Survey and Bibliography of Studies on Renaissance Aristotelianism, 1958-1969, Padua.

Schmitt 1983: C. B. Schmitt, Aristotle and the Renaissance, Cambridge, Massachusetts and London.

Schmitt 1988: C. B. Schmitt, "The rise of the philosophical textbook", en The Cambridge History of Renaissance Philosophy, (C. B. Schmitt, et al. eds.), Cambridge, pp. 792-804.

Sgarbi 2012: M. Sgarbi, "Towards a Reassessment of British Aristotelianism," en Vivarium, 50, pp. 85-109.

Skulsky 1968: H. Skulsky, "Paduan Epistemology and the Doctrine of the One Mind," en Journal of the History of Philosophy, 6, pp. 341-361.

South 2002: J. B. South, "Zabarella and the Intentionality of Sensation”, en Rivista di storia della filosofia, 57, pp. 5-25.

South 2005: J. B. South, "Zabarella, Prime Matter, and the Theory of Regressus", en Graduated Faculty Philosophy Journal, 26.

Spruit 1994: L. Spruit, Species Intelligibilis. From Perception to Knowledge. Vol. I: Classical Roots and Medieval Discussions, Leiden.

Spruit 1995: Leen Spruit, Species Intelligibilis. From Perception to Knowledge. Vol. II: Renaissance Controversies, Later Scholasticism and the Elimination of the Intelligible Species in Modern Philosophy, Leiden.

Spruit 2008: L. Spruit, Renaissance Views of Active Perception, en Theories of Perception in Medieval and Early Modern Philosophy, (S. Knuuttila, P. Kärkkäinen eds.), Dordrecht.

Tomasino 1630: G. Tomasino, Illustrium virorum elogia, Patavii, apud Donatum Pasquardum.

Valverde 2009: J. M. García Valverde, “Introduzione” en A. Nifo, L'immortalità dell'anima, Milán.

Valverde 2012르. J. M. García Valverde, "El comentario de Giacomo Zabarella a De anima III, 5: una interpretación mortalista de la psicología de Aristóteles", en Ingenium, 6, pp. 27-56.

Vasoli 1968': C. Vasoli, La Dialettica e la retorica del'Umanesimo, Milan.

Vasoli 19682: C. Vasoli, Studi sulla cultura del Rinascimento, Manduria.

Vasoli 2011: C. Vasoli, “Jacopo Zabarella e la 'natura' della logica,” en Rivista di storia della filosofia (new series), 66, pp. 1-22.

Wallace 1988: W. A. Wallace, "Traditional natural philosophy", en The Cambridge History of Renaissance Philosophy, (C. B. Schmitt, et al. eds.), Cambridge, pp. 201-235. 